REVISTA ANDALUZA DE ANTROPOLOGÍA

NÚMERO 19: DÍAS EXTRAÑOS. CÓMO EL COVID-19 TRANSFORMA NUESTRA COTIDIANIDAD DICIEMBRE DE 2020

ISSN 2174-6796

[pp. 151-173]

https://dx.doi.org/10.12795/RAA.2020.19.10

\title{
SEÑORAS DE LA TRADICIÓN. MUJERES FOLKLORISTAS EN CUBA
}

\author{
Carmen Ortiz García \\ Instituto de Historia. CSIC
}

\section{RESUMEN}

En la historia de la antropología cubana se ha prestado relativa poca atención a varias mujeres que, sin embargo, han obtenido reconocimiento profesional por parte de la comunidad académica internacional. Calixta Guiteras Holmes sería uno de estos casos, con sus caracteres particulares. Otra mujer menos conocida pero relevante fue Carolina Poncet de Cárdenas, que formó una generación de mujeres pedagogas y folkloristas muy activas. En un lugar diferente habría que situar la obra y la trayectoria vital de la que puede considerarse como fundadora moderna de los estudios sobre las religiones afrocubanas, la escritora y antropóloga Lydia Cabrera, quien solo recientemente ha empezado a formar parte de la nómina intelectual en la cultura cubana oficial. Se aborda un examen de estas tres figuras y se analizan sus contribuciones a la antropología, partiendo de la idea de que en el relato hegemónico de la historia de las ciencias el papel de fundadores ha estado generalmente en manos de hombres. Asimismo, se trata la cuestión de la visibilidad y la continuidad institucional y de sus líneas de investigación en el mundo académico cubano dedicado a la antropología y el folklore, con el objetivo final de poner en primer plano las contribuciones de estas mujeres investigadoras.

Palabras Clave: Historia de la antropología y el folklore; Mujeres científicas; Folklore infantil; Culturas afrocubanas; Calixta Guiteras, Carolina Poncet, Lydia Cabrera. 


\section{ABSTRACT}

In the history of Cuban anthropology, little attention has been paid to several women who have, nevertheless, obtained professional recognition from the international academic community. Calixta Guiteras Holmes is one such case, with her unique characters. Another less known but equally relevant woman was Carolina Poncet de Cárdenas, who formed a generation of highly active female pedagogues and folklorists. A different place is required to situate the life and work of a person who could be considered the modern founder of studies on Afro-Cuban religions, the writer and anthropologist Lydia Cabre$\mathrm{ra}$, who has only recently begun to be acknowledged by intellectual circles in official Cuban culture. An examination of these three figures is undertaken, and their contributions to anthropology are analyzed, opposing the hegemonic account of the history of science where the role of founders has generally been attributed to men. Likewise, the issues of institutional visibility and continuity and the lines of research in the Cuban academic world dedicated to anthropology and folklore are discussed, with the ultimate goal of bringing the contributions of these women researchers to the fore.

Keywords: History of anthropology and folklore; Scientific women; Children's Folklore; Afro-Cuban cultures; Calixta Guiteras, Carolina Poncet, Lydia Cabrera.

\section{INTRODUCCIÓN ${ }^{1}$}

En la historia de las ciencias y del conocimiento, uno de los sesgos, presente en la historiografía general, pero tal vez aún más acusado cuando se trata de la actividad científica, es el androcentrismo. La ciencia parece haber sido hasta hace muy poco una actividad en manos exclusivamente de los hombres. El relato histórico, las narraciones disciplinares, nacionales o de escuela, acerca de cómo se desarrollaron las teorías científicas y las prácticas investigadoras han tenido, y tienen, un indudable sesgo de género. Por tanto, una de las aproximaciones actuales más necesarias y renovadoras es la inclusión de un enfoque feminista en la investigación histórica especializada (Jordanova, 1993; Mayberry, Subramaniam y Weasel, 2002). Los enfoques teóricos feministas pueden ser muy diversos, como también lo son sus aplicaciones a conocimientos o prácticas de trabajo en campos científicos distintos. Uno de sus principales tipos, por afectar a la base misma de la investigación, trata del problema de la ausencia o la invisibilización

1. Este trabajo se ha llevado a cabo formando parte del Proyecto "Connected Worlds: The Caribbean, Origin of Modern World" (ConnecCaribbean). Este Proyecto ha recibido fondos del programa de investigación e innovación Horizonte 2020 de la Unión Europea en virtud del acuerdo de subvención Maria Sklodowska-Curie no 823846 . El Proyecto está dirigido por la profesora Consuelo Naranjo Orovio, del Instituto de Historia-CSIC. Una versión oral fue presentada en el Seminario "El Caribe: Un acercamiento interdisciplinario", organizado por el CSIC y la Universidad del Turabo, de Puerto Rico, en el Instituto de Historia del CSIC, en Madrid, en 2018. Agradezco a los investigadores de este proyecto sus comentarios y especialmente a Víctor Fernández sus críticas y atinadas correcciones. Las sugerencias de los lectores anónimos del manuscrito me han sido igualmente de gran utilidad. 
de las mujeres en la historia de las disciplinas científicas. De aquí que muchos estudios feministas en historiografía científica intenten el rescate o la búsqueda de las mujeres científicas, acerca de las cuales muchas veces la información documental falta o es escasa (Davis, 1975; Harding, 1995).

Por encima de lo que podemos considerar el simple rescate historiográfico de algunas mujeres están, por supuesto, los problemas teóricos y metodológicos que plantea una historiografía de cualquier ciencia realizada con perspectiva de género (Harding, 1998; Gregorio, 2006). No obstante, la elaboración de una historia feminista de la ciencia ha puesto de manifiesto, como uno de los aspectos metodológicos que la diferencian, la importancia del carácter personal y/o biográfico de esta misma historia (Bolufer, 2014; Santesmases, Cabré y Ortiz, 2017).

En la historia de las ciencias antropológicas la aparición de mujeres no supone ninguna novedad. De hecho, algunas antropólogas importantes, como Margaret Mead y Ruth Benedict, o más recientemente Mary Douglas, son consideradas como "madres" o fundadoras de escuelas teóricas de gran relevancia. Sin embargo, los relatos acerca del desarrollo de las disciplinas antropológicas han estado tradicionalmente copados por las figuras masculinas (Stolcke, 1993). Por otro lado, el folklore, ocupado en el estudio de los estilos expresivos y artísticos de las distintas colectividades, precisamente por centrarse en los materiales de creación literaria, musical, artesanal, indumentaria, etc., ha sido con frecuencia relegado como una disciplina menor entre las prácticas diferentes que se rubrican dentro de la antropología y, tal vez por ello, en él las mujeres han tenido un papel más amplio que en otras especialidades antropológicas.

El texto pretende exponer los trabajos y las trayectorias de una serie de mujeres dedicadas a la antropología y el folklore en Cuba. A través de sus vidas, y apreciando en ellas de qué manera el ser mujeres, junto a otros factores y contextos sociales y políticos, pudo condicionar su trabajo, además de su consideración posterior, se buscará establecer las líneas de continuidad de la práctica investigadora y los hilos que unen sus trayectorias con la comunidad profesional actual, a pesar de que no hayan sido explícitamente puestas en valor por la historiografía.

La historia de la antropología hecha en Cuba ha puesto el acento en tres aspectos fundamentales. En primer lugar, está la cuestión de la ausencia de una profesionalización universitaria para la disciplina antropológica (Korsbaek y Barrios, 2009). Por otro lado, la presencia hegemónica de Fernando Ortiz ha contribuido a hacer una historia personalista, muy centrada en la figura de este gran patriarca (Santí, 2002). En tercer lugar, y sobre todo, se ha recalcado la importancia de la investigación en torno a las religiones afrocubanas, lo que ha hecho que tanto la etnografía como la historia de la antropología estén mayoritariamente dirigidas hacia esta importante parcela de la cultura nacional (Dianteill, 1995; Palmié, 2013; Lescay, 2017). 
Sobre los fundadores de los estudios antropológicos cubanos en general (Barnet, 1983; Guanche y Campos, 1986; Barreal, 2001; Santí, 2002; Castellanos, 2003; RodriguezMangual, 2004; Rangel, 2012; Galván, 2018), y dentro de ellos los dedicados concretamente al folklore (Aguirre, 1975; Mesa, 2008; Quiza, 2014), se suele partir de una trinidad fundacional, enunciada por Jorge Castellanos (2003) y dedicada en concreto a los estudios afrocubanos, que está constituida por Fernando Ortiz, como figura indiscutible, flanqueado por otros dos autores relacionados con él; su discípulo y crítico a la vez, Rómulo Lachatañeré (1909-1951), desaparecido prematuramente y autor del primer intento de clasificación de los orígenes étnicos de los cultos afrocubanos, y Lydia Cabrera, que mantuvo estrechos lazos, incluso familiares, con Ortiz.

Frente a este relato tradicional, nos interesa aquí resaltar otra "tríada", en este caso femenina exclusivamente, y que además está también relacionada de múltiples formas con Ortiz. Siguiendo la conocida metáfora orticiana que representaba la identidad cultural cubana y su mestizaje como un "ajiaco" o "melting pot", es decir, un prístino caldero en el que se iban añadiendo y se cocían a fuego lento los aportes étnicos (también habla de las diferentes "tierras") de los ancestros aborígenes, los africanos esclavizados en la colonia y los europeos dominantes económica y políticamente (Ortiz, 1940) ${ }^{2}$, encontramos tres influyentes mujeres investigadoras, dedicadas cada una de ellas a trabajar en una de las distintas raíces cubanas, de forma paralela e independiente de Fernando Ortiz. Se exponen los trabajos de Calixta Guiteras, dedicada a la antropología amerindia; Carolina Poncet y su escuela de pedagogas, que exploraron el folklore de tradición hispánica; y Lydia Cabrera, que se ocupó de manera magistral de las tradiciones religiosas afrocubanas. Ellas son las figuras descollantes, y en torno a ellas hubo otras mujeres que dedicaron su trabajo al conocimiento de las raíces y la identidad cultural de su país. La historia de la antropología en Cuba comienza con algunos antecedentes en el periodo colonial, pero se desarrolla de forma profesional coincidiendo con la independencia y el establecimiento de la República neocolonial. La Revolución supone un corte con respecto a la tradición y los autores anteriores, e inaugura una serie de instituciones dedicadas a la revisión y el mantenimiento de la interpretación antropológica de la realidad cultural cubana siguiendo modelos marxistas, aunque no excesivamente ortodoxos. El folklore, la música, la danza y las manifestaciones literarias se consideraron en cualquiera de estos periodos parte de las disciplinas antropológicas.

\section{CALIXTA GUITERAS HOLMES (1905-1988)}

La rápida extinción de los aborígenes de la isla de Cuba tras el primer choque colonial hace que su conocimiento cultural haya sido más obra de la arqueología y la etnoarqueología

2. Este argumento de las tres "tierras" fundadoras de Cuba no mantiene toda su vigencia actualmente y tampoco es válido como una característica interna en la obra y los intereses específicos de la investigación de las autoras que son objeto de este trabajo. Se utiliza únicamente como metáfora útil dentro de nuestro argumento analítico. 
que de la etnografía propiamente dicha. No obstante, una de las pocas figuras internacionalmente reconocidas de la antropología cubana, Calixta Guiteras Holmes, lo es por su dedicación a la investigación de las etnias de cultura maya del cercano territorio mexicano. Puede ella servir, pues, de representante de esa tierra "roja" a la que se refería Ortiz como componente del suelo ancestral Caribe.

Guiteras, aunque reputada internacionalmente por su trabajo indigenista en México, era cubana (si bien nacida en Estados Unidos), siendo una figura muy comprometida políticamente desde sus años de estudiante de Filosofía en la Universidad de La Habana, donde, al igual que su hermano Antonio (Tony), líder socialista, formó parte del Directorio Estudiantil Revolucionario y se involucró en la lucha contra la dictadura de Gerardo Machado. La muerte de Antonio Guiteras en 1935, asesinado por la policía de Batista, llevó a Calixta al exilio mexicano, donde culminó sus estudios en 1942 en la recién creada Escuela Nacional de Antropología e Historia. Posteriormente, fue profesora en esta Escuela, en la UNAM y en la Universidad de Mérida (Castro, 2000).

A partir de 1942 realizó trabajo de campo sobre los sistemas de parentesco y creencias tzeltales en Chiapas (Zinacaután, Cancuc, Chelanhó, Chalchihuitán, Chanal y Bachajón), primero formando parte del proyecto dirigido por Sol Tax y Alfonso Villa Rojas, y más tarde investigando sobre la cosmovisión y las creencias religiosas de los tzotziles bajo el patrocinio de Robert Redfield y con una beca de la Universidad de Chicago entre 1952 y 1956 (Esponda et al., 1994). La publicación de esta etnografía, primero en inglés (1962) y luego en español (Los peligros del alma. Visión del mundo de un tzotzil, Guiteras 1965b), consagró internacionalmente a Guiteras, que había vuelto a Cuba tras el triunfo de la Revolución, en 1961. La monografía de Guiteras es uno de los libros más influyentes de los que se hicieron como parte de los trabajos de campo patrocinados por Redfield y la poderosa Universidad de Chicago en México. La comunicación establecida entre la autora y el especialista religioso Manuel Arias Sojom, y la manera en la que Guiteras traslada la cosmovisión zotzil, logra una etnografía que fue utilizada como modelo en la enseñanza de la antropología en muchas universidades del mundo.

La etapa cubana de su carrera es menos conocida y en ella Guiteras, que ya se había desempeñado como una magnífica profesora en México, se dedicó fundamentalmente a la docencia en el Instituto de Etnología y Folklore. Este centro fue creado en diciembre de 1961 por el Consejo Nacional de Cultura. Guiteras formó parte de su órgano directivo y entre 1970 y 1973 fue profesora de Antropología General y dirigió proyectos y trabajos etnográficos hasta su jubilación en 1975. En estos años siguió manteniendo sus contactos en México y publicando algunos artículos dedicados a Chiapas, como el que apareció en el número inaugural de la Revista de Etnología y Folklore, órgano del Instituto, y en Cuba se hicieron también dos ediciones de Los Peligros del Alma, en 1972 y en 1988 (Pérez Álvarez, 2011). Finalmente, en 2011, en la colección de antropología titulada La Fuente 
Viva de la Fundación Fernando Ortiz de La Habana, apareció un volumen con once de sus trabajos dedicados a los grupos mayas y huastecas, compilados e introducidos por el historiador y antropólogo especialista en la cultura tzeltal, Víctor Manuel Esponda (Guiteras, 2011) .

A pesar de que los trabajos de campo que hicieron famosa a Guiteras se desarrollaron en Chiapas, formando parte de los proyectos liderados por Sol Tax y Robert Redfield de la escuela de antropología social de la Universidad de Chicago, y de que apenas dedicó sus esfuerzos investigadores a temas cubanos, sus lazos académicos y personales con su país de origen tuvieron gran importancia. Esto se manifiesta sobre todo en su labor docente y como directora de trabajos etnográficos en la Cuba de las primeras décadas de la Revolución, que ha sido reconocida por sus alumnos en el Instituto de Etnología y Folklore, entre ellos, por ejemplo, Miguel Barnet. Con todo, Calixta Guiteras es conocida internacionalmente como una importante etnógrafa por sus trabajos de campo en distintas zonas de Chiapas, donde la penetración occidental había sido traumática y donde desarrollar una observación participante como la que ella logró no estaba al alcance de muchos. Por tanto, sus enseñanzas partían de una experiencia práctica en el campo profesional de primer orden.

Así, es significativo de la importancia que Guiteras daba al trabajo de campo etnográfico el artículo que publicó en el homenaje que la revista Gaceta de Cuba dedicó a Ortiz en 1965. En él, además de reivindicar el papel político de Ortiz - llegando a entroncarle con los grandes revolucionarios antiimperialistas, incluido su propio hermano-, destacaba la visión personal que proporcionaban sobre el "doctor" dos de sus colaboradores, los músicos Raúl Díaz y Trinidad Torregrossa, a los que Guiteras entrevistó sobre su relación y las circunstancias de su trabajo como informantes de Ortiz, y que mostraban a un antropólogo de campo - o de calle - algo diferente de la figura erudita y más libresca que es tradicional en las semblanzas de Ortiz (Guiteras, 1965a).

\section{CAROLINA PONCET Y DE CÁRDENAS (1879-1969)}

Otra de las "tierras" o de las "carnes" componentes del "ajiaco" cubano es la europea. Trabajando sobre ella, en una disciplina distinta a la antropología social y con los métodos y principios propios del estudio folklórico en un periodo cronológico anterior al del trabajo de Guiteras, encontramos a otra mujer, Carolina Poncet y de Cárdenas, también, como Guiteras, emparentada con una familia políticamente muy influyente, aunque de signo ideológico diferente; conservador. Tras graduarse en 1897 comenzó su carrera como maestra de niñas en La Habana, distinguiéndose tanto en la enseñanza que

3. Acerca de la actividad de Calixta Guiteras en Cuba, ver Rafael Rojas, "Guiteras en Chiapas". Blog Libros del crepúsculo, 20-1-2011; y Frank Pérez Álvarez, "Carta a Rafael Rojas”, Blog. Libros del crepúsculo, 28-10-2011. Disponible en http://www.librosdelcrepusculo.net/ [consultado 20-9-2020]. 
en 1903 fue premiada, como "mejor maestra del país", con un viaje a la Universidad de Harvard para seguir un curso de pedagogía. Por estos años publicó la obra Lecciones de lenguaje, que sirvió durante muchos años como texto oficial en las escuelas de Cuba, con reediciones al menos hasta 1947. Se graduó en la Universidad de La Habana en 1913 con una tesis sobre El Romance en Cuba que obtuvo el Premio Nacional de Artes y Letras y que se publicó en 1914 (Poncet, 1914).

La pedagogía ha sido tradicionalmente uno de los ámbitos en que la labor profesional de las mujeres tenía una mayor acogida. Sin embargo, y a pesar de su brillante historial, Poncet no obtuvo la cátedra de la Escuela de Pedagogía de la Universidad de La Habana, a la que optó en 1915. La reticencia del tribunal de esta oposición a otorgarle el puesto por su condición de mujer llegó incluso a tener resonancia en la prensa habanera, con artículos que aludían a esta circunstancia publicados en La Prensa o el Diario de la Marina (Ortega, 2004). En esta tesitura, Carolina Poncet renunció a sus aspiraciones universitarias, ganando en cambio el puesto de catedrática de Gramática, Composición, Elocución, Literatura Cubana y Española de la Escuela Normal de Maestros de La Habana. Su carrera profesional transcurrió en este centro, del que llegó a ser directora. En 1931 fue separada temporalmente de la cátedra por el decreto del Presidente Machado que ordenaba el cierre de todos los centros de enseñanza superior de la isla, siendo de nuevo apartada en 1935 por su participación en la huelga general contra el gobierno (Ortega, 2004). En 1920, durante un periplo europeo, viajó a España para asistir en Madrid a un curso de Ramón Menéndez Pidal (Barnet, 1983: 126-127), pasando a formar parte de la amplia red que estaba estableciendo este para configurar los archivos del romancero americano, como parte fundamental del proyecto de recopilación del género romancístico hispano (Menéndez Pidal, 1906).

Al igual que otro hispanista cubano colaborador de Fernando Ortiz, José María Chacón y Calvo -quien en el mismo año de 1914 también había publicado un importante trabajo sobre los romances tradicionales de Cuba (Chacón y Calvo, 1914)_, Carolina Poncet formó parte de la primera Junta Directiva de la Sociedad El Folklore Cubano, que Ortiz organizó en 1923. También participó en el Consejo de Redacción de su revista, Archivos del Folklore Cubano (1924), en la que publicó una serie de trabajos dedicados a la literatura oral de tradición hispánica ${ }^{4}$ (Ortiz García, 2003: 703-706). En 1955 fue nombrada Catedrática Emérita y en 1960 designada miembro de la Academia Cubana de la Lengua (Trapero y Esquenazi, 2002: 39). Aunque conservadora y católica, no quiso abandonar Cuba tras el triunfo de la Revolución.

En 1972 se reeditó su libro El Romance en Cuba y en 1985 salió una recopilación con los escritos de Carolina Poncet reunidos por Mirta Aguirre. En 1999 se puso su nombre

4. "Cantares locales cubanos" (1924), "Los altares de cruz" (1926), "Romancerillo de Entrepeñas y Villar de los Pisones" (1928) y "Romances de Pasión” (1930). 
a una Cátedra de Estudios de Oralidad creada en el Instituto de Investigación Cultural Juan Marinello de La Habana. Asimismo, su tesis fue reeditada en 1999 dentro de la colección La fuente viva de la Fundación Fernando Ortiz y en 2004 se publicaron unas Reflexiones teórico-prácticas desde las ciencias de la educación, todo lo cual muestra el interés de los académicos cubanos por recuperar su figura y su obra. Con todo, a pesar de ser una mujer pionera en los medios universitarios y de sus indudables méritos, Carolina Poncet no alcanzó gran relevancia académica (Barnet, 1983: 127).

De igual manera, las figuras en gran medida paralelas de Carolina Poncet y de José María Chacón (Mesa, 2008; Guillama, 2019), pese a ser consideradas por los especialistas junto a Julio Vicuña Cifuentes en Chile, Ciro Bayo en Argentina y Pedro Henríquez Ureña en República Dominicana- como pioneras en el estudio del romancero en América (Trapero y Esquenazi, 2002: 39), han sido relegadas por la historiografía cubana hasta hace poco. Este hecho podría explicarse por la negación por parte de la Revolución de la obra cultural e intelectual de las generaciones anteriores, al considerarlas, no solo burguesas, sino también dependientes de una visión colonialista de la nación. En esa postergación pudo influir también la importancia dada por la Revolución a los orígenes africanos y la hibridación de la población como elementos configuradores de la identidad de la nueva Cuba frente a los aportes procedentes de la antigua metrópoli colonial (De la Fuente, 2001; Bronfman, 2004).

\section{LA ESCUELA DE CAROLINA PONCET. MAESTRAS Y RECOPILADORAS DE MATERIAL FOLKLÓRICO}

La escasa relevancia académica de Poncet se compensó sobradamente con una incesante labor pedagógica, de la que surgió toda una generación de mujeres, formadas en la Escuela Normal y que se desempeñaron luego profesionalmente como profesoras de enseñanza secundaria, se introdujeron en la recopilación folklórica y dieron a conocer sus propias investigaciones a través de libros y artículos, muchos de ellos publicados en los Archivos del Folklore Cubano. Por lo tanto, puede hablarse de una línea de continuidad en la recopilación de expresiones de cultura popular folklórica, que parte de Carolina Poncet y llegaría hasta la actualidad.

En este grupo de folkloristas la labor investigadora sobre la cultura popular de origen hispánico estuvo íntimamente relacionada con su desempeño pedagógico. Este sesgo marca el carácter de las tradiciones orales que recogieron, por tratarse sobre todo de encuestas sobre folklore en la escuela, y ha llevado a los especialistas actuales a plantear y discutir si la pervivencia, por ejemplo, de romances y canciones de tradición hispánica se dio sobre todo entre los niños y las niñas. Es decir, si las pervivencias culturales españolas se han mantenido fundamentalmente en el folklore infantil cubano (Trapero y Esquenazi, 2002: 35). 
Sobre ese tema, en varias entregas de los Archivos, desde su primer número de 1925, se publicó la memoria para el grado de doctora en Pedagogía presentada en 1923, en la Universidad de La Habana, “El folklore del niño cubano” por Sofía Córdova de Fernández (1925-1929) ${ }^{5}$. En la misma Escuela de Pedagogía habanera se presentó otra tesis debida a Consuelo Miranda, titulada "Las supersticiones de los niños cubanos", también publicada en los Archivos en 1929. Con el mismo cuestionario y temática idéntica, pero con datos recogidos en este caso en las escuelas de Santiago de Cuba, de cuya Escuela Normal era profesora, se incluyeron el trabajo de Manuela Fonseca García, "Las supersticiones del escolar cubano" (1930) y el firmado por Dolores Hernández Suárez, "Cuentos recogidos en Camagüey" (1929-1930). De esta misma autora se cita también una recopilación de juegos infantiles cubanos y de Esperanza Valdés Rodríguez, "Agüeros que son creídos en Cuba" (Prat, 2008: 250).

La contribución de esta rama filológica, clásica en el folklore europeo, centrada en el estudio de la literatura oral y popular española, formaba parte de la idea que Fernando Ortiz tenía de cómo debía abordarse el conocimiento de la cultura tradicional cubana, que concebía como una obra colectiva y de trascendencia política en la constitución de la identidad nacional - la cubanidad - en la moderna República. En esta labor se empeñó Ortiz de múltiples maneras, y una de las instituciones básicas promovidas fue la Sociedad del Folklore Cubano, cuyo objetivo era recopilar y publicar el acervo de las formas expresivas del pueblo (Ortiz García, 2003; Mesa, 2008; Quiza, 2014). Ortiz se refiere en el artículo inaugural de la revista de la Sociedad a las tres grandes fuentes de ese "caudal folklórico"; las tres "tierras" y sus "labradores":

“Apenas Carolina Poncet y José $\mathrm{M}^{\mathrm{a}}$ Chacón y Calvo dieron a la tierra blanca unos hierros de su incansable energía investigadora en busca de romances enterrados, cuando unos ricos y bien castizos ejemplares brotaron a la luz. Bachiller y Morales se aventuró hace ya algunos lustros en la tierra roja, con los pobres métodos de su tiempo, y su genio descubrió muchas raíces indias con enmarañadas ramificaciones hasta el día. Cruzó las tierras prietas y mulatas Fernando Ortiz, y en los surcos de la investigación aparecieron ritos, leyendas, músicas y lenguajes que se creían muertos o de cuya existencia en Cuba nada se sabía, y toda una vida no ha de bastar para el estudio del fondo africano de la demopsicología de estas Indias aun en parte por descubrir" (Ortiz, 1924: 7).

Por otro lado, José María Chacón y Fernando Ortiz incluyeron la cultura popular y el folklore español entre las materias que resultaban interesantes en su labor de establecer lazos intelectuales permanentes entre España y Cuba a través de la Institución Hispanocubana de Cultura (Del Toro, 1996). Chacón tuvo así una importancia capital

5. Trabajo publicado previamente en varias entregas en la Revista de la Facultad de Letras y Ciencias, 33 (3-4) (1923): 268-306; 34 (1-2) (1924): 26-52; 35 (1-2) (1925): 109-156; 35 (3-4) (1925): 361-418. 
en la realización de la estancia en Cuba, prolongada durante cinco meses, de Ramón Menéndez Pidal en 1937, dentro de la movilización de la Hispanocubana en ayuda de los republicanos españoles, una vez declarada la guerra en 1936 (Puig-Samper y Naranjo, 2001). Este viaje propició el contacto del prestigioso filólogo español con el grupo de mujeres que se habían formado con Carolina Poncet. De hecho, después de las conferencias impartidas por Pidal en La Habana, Chacón le acompañó en una excursión folklórica en la que se produjo un encuentro con estas profesoras, que le facilitaron la recogida de romances y otros materiales en escuelas de Santiago de Cuba y Camagüey (Chacón, 1994).

La música es inseparable de la expresión literaria en el folklore. En este terreno, otra mujer importante en la investigación folklórica cubana, coetánea de Carolina Poncet, fue la musicóloga María Muñoz Portal (1886-1947), nacida en España y nacionalizada cubana en 1940 (Del Río, 2016). Además de su obra como música, directora coral, editora de revistas musicales y docente, María Muñoz colaboró con la Institución Hispanocubana en la organización en 1931 de un Festival de Música Folklórica, en el que actuó La Sociedad Coral de La Habana, que ella dirigía, e impartió una conferencia sobre "Pueblo, panorama y folklore hispánico" (Del Toro, 1996: 27). María Muñoz también participó en otra iniciativa de Ortiz, los cursos de antropología organizados en la Escuela de Verano de la Universidad de La Habana, en los que se encargó de la docencia de música folklórica entre 1941 y 1945. En 1947 todavía aparece Fernando Ortiz disertando en esos cursos sobre músicas populares cubanas (García-Carranza, 1970: 30); uno de los principales intereses de su investigación desde la década anterior. Posteriormente, Argeliers León Pérez (1918-1991), alumno de esta escuela de verano y discípulo de María Muñoz, creará un curso de especialización sobre música folklórica que será continuado por María Teresa Linares. Argeliers León será el personaje más influyente en los organismos creados por la Revolución dedicados al folklore y la antropología, desde sus puestos como director del Instituto de Estudios de Etnología y Folklore y del Centro de Estudios Africanistas (Barnet, 1983: 132-135).

Algo más joven que María Muñoz Portal fue otra mujer dedicada a la música y a su enseñanza, la soprano Zoila Gálvez Pérez (1900-1985). Gálvez fue una intérprete famosa que actuó con éxito en el circuito lírico por Europa y Estados Unidos, pero por sus conocimientos sobre la música afrocubana también se cuenta entre las mujeres que colaboraron con Fernando Ortiz, tanto en actividades organizadas por la Institución Hispanocubana de Cultura, como en la Sociedad de Estudios Afrocubanos, de la que formaba parte (Pérez Valdés, 2014-2016, 2: 348).

\section{LÍNEAS DE CONTINUIDAD FOLKLÓRICA}

Esa generación de mujeres folkloristas y pedagogas que hemos visto en acción a partir de las enseñanzas de Carolina Poncet tuvo cierta continuidad. En 1940 se publica el 
Folklore sagüero, con la recopilación hecha por los alumnos de Gramática y Literatura Hispanocubana del Instituto de Segunda Enseñanza de Sagua la Grande, bajo la coordinación de Ana María Arissó Fernández (1913-¿?) (Barreal, 2001: 132-143), quien entre 1938 y 1940 había asistido a los cursos de verano sobre música y folklore de la Universidad de La Habana. El concepto tradicional de la creación literaria popular que tenía Arissó y su utilización pedagógica con el alumnado se aprecian en otros proyectos que coordinó en el Seminario de Redacción que ella había creado en el Instituto de Sagua, para rendir homenaje a glorias de la literatura nacional (Barreal, 2001: 133-134).

Ya en el período de la Revolución, la Dirección de Investigaciones Folklóricas publica, con un prólogo de Samuel Feijóo, los dos volúmenes de folklore infantil recogidos por Concepción Teresa Alzola (1930-2009) (Alzola 1961-1962). El primero está dedicado a las expresiones literarias y el segundo a los juegos. La recopilación está hecha con una sistemática más avanzada que la de Arissó (Barnet, 1983: 212), incluyendo las partituras musicales (debidas a María Álvarez Ríos) de los textos cantados, así como los datos personales de sus informantes, fundamentalmente sus alumnos - ya que ella era profesora de enseñanza especial-, pero también otros estudiantes de la Universidad de La Habana y la Escuela de Comercio de Marianao (Trapero y Esquenazi, 2002: 46). Esta autora seguirá publicando recopilaciones de expresiones populares cubanas en la Asociación de Hispanistas de las Américas, desde su exilio en Miami: La más fermosa: [leyendas cubanas] (1975) y Habla tradicional de Cuba: Refranero familiar (1987a). Aparece también invitada a participar en el homenaje a Lydia Cabrera que editarán Isabel Castellanos y Josefina Inclán con motivo del cincuentenario de la publicación de los Cuentos negros de Cuba (Alzola, 1987b). Finalmente, su último libro, salido en 2009, está dedicado a la historia de las mujeres en $\mathrm{Cuba}^{6}$.

Otra muestra de continuidad, esta vez en el interior de la isla, será la labor de la poeta e intelectual comunista y feminista Mirta Aguirre (1912-1980), cuya madre, Aída Carreras, que fue profesora de música en la Escuela Normal de Matanzas, había sido informante de Concepción Teresa Alzola en 1951 (Alzola, 1961-62, I: 30). En su trabajo como especialista en literatura hispánica, Aguirre incluye el género romancístico, publicando al respecto varios trabajos teóricos y de recopilación $(1975,1985)$. Los especialistas en el romancero han destacado que esta atención es excepcional entre los intelectuales cubanos del siglo XX (Trapero y Esquenazi, 2002: 49). A la vez, desde sus puestos como profesora de literatura en la Universidad de La Habana, como directora (desde 1976 hasta 1980) del Instituto de Literatura y Lingüística de la Academia de Ciencias de Cuba y también como directora de la Sección de Teatro y Música del Consejo Nacional de Cultura de la Revolución, promovió las actuaciones e investigaciones folklóricas. En este

6. La correspondencia y otros documentos del archivo de esta autora se conservan en la University of Miami Cuban Heritage Collection. Concha Alzola Collection (CHC0493). 
sentido, es destacable que a ella se debe el rescate de la obra de Carolina Poncet, una figura relativamente distante ideológica y socialmente de su propia trayectoria. Mirta Aguirre fue la editora del libro póstumo de Poncet, Investigaciones y apuntes literarios (1985) que reúne no solamente los estudios que publicó en su día y alguno inédito, como la conferencia "Coplas y romances de Navidad" (Poncet, 1985: 572-609), sino que en un "Apéndice" (Poncet, 1985: 610-665) publica los romances recogidos por ella y por otros que permanecían manuscritos en el archivo de Carolina Poncet conservado en el Instituto de Literatura y Lingüística de La Habana (Trapero y Esquenazi, 2002: 40-41) 7 .

Si en el periodo de la Revolución es relevante la figura de Mirta Aguirre, en el campo de la literatura tradicional, su contrapeso en el terreno del folklore musical cubano es María Teresa Linares (1920), acompañada en este caso por su marido Argeliers León, con el que comenzó a realizar trabajo de campo ya en 1948 para documentar la música popular, tanto de tradición hispánica como afrocubana, y con el que trabajó en el Instituto de Etnología y Folklore. Los libros (Linares, 1970; Linares y Núñez, 1998) y sobre todo las grabaciones llevadas a cabo durante años por María Teresa Linares para la Empresa de Grabaciones y Ediciones Musicales (EGREM), creada por el Estado en 1964, no solo se dedicaron a la tradición europea, sino que paulatinamente las músicas y danzas de origen africano fueron cobrando mayor visibilidad hasta hacerse preponderantes.

\section{LYDIA CABRERA BILBAO (1899-1991)}

Hay que tener en cuenta que el folklore de tradición europea, pasado por el tamiz hispánico, no era lo más novedoso en los estudios sobre cultura popular en Cuba en las primeras décadas del siglo XX. Lo que diferenciaba de otras a la cultura cubana era la abundante contribución de la población afrodescendiente y, en función de esto, cobraron importancia los investigadores que se dedicaban al estudio de sus rasgos trasplantados.

Volviendo a la imagen de las tres tierras que, según Ortiz, era necesario labrar (a las que más tarde añadiría, en la presentación de la Sociedad de Folklore Cubano, la amarilla de la inmigración china), la tercera persona de la inicial tríada femenina que mencionábamos al principio como fundadoras del folklore cubano es Lydia Cabrera Bilbao, que se dedicó durante su larga vida al estudio de la religión y las tradiciones legendarias de los descendientes de africanos esclavizados de su isla natal. Lydia Cabrera es la "madre" de los estudios afrocubanos y una impulsora imprescindible en el reconocimiento de la importancia, la legitimidad y la diferencia de la aportación cultural de los afrodescendientes en la configuración de la historia y la identidad cubana y caribeña. Cabrera murió en el exilio de Miami, a donde se trasladó en 1960 (Hiriart, 1983).

7. Los romances que fueron recogidos por Poncet de sus informantes españolas emigradas a Cuba han sido editados de nuevo como Apéndice (pp. 491-533) en el Romancero tradicional y general de Cuba de estos mismos autores. Asimismo, estaban ya incluidos en el Romancero de Beatriz Mariscal (1996). 
Lydia era la hija menor del matrimonio formado por Elisa Bilbao y Raimundo Cabrera, un relevante abogado y periodista, miembro de la generación de intelectuales y políticos denominada del sesenta y ocho, comprometido políticamente en la lucha por conseguir la independencia de España. Sus orígenes familiares y su género parecían dirigir a Lydia Cabrera por los derroteros habituales en las mujeres de su clase. Así, su primera vocación fue la pintura y para aprender arte se instaló en París en 1927, donde coincidió con los jóvenes escritores que conforman el movimiento de la Negritude. No obstante, las biógrafas de Cabrera (Hiriart, 1983; Castellanos e Inclán, 1987; Gutiérrez, 1991; Rodriguez-Mangual, 2004; Sánchez Morales, 2016) coinciden con la propia autora en que será el reencuentro con su infancia y con los afrocubanos, redescubiertos a través de su extrañamiento europeo, lo que a partir de ese momento constituirá su dedicación absoluta y dirigirá su vida. Una figura central que propiciará la inclinación de Lydia Cabrera hacia la literatura y las tradiciones orales afrocubanas es su compañera en esos años, Teresa de la Parra, una escritora venezolana ya consagrada, que murió muy joven en 1938. Para ella Lydia escribió los Contes nègres de Cuba, publicados en 1936 por la editorial Gallimard.

El ambiente bélico en Europa y la muerte de Teresa de La Parra deciden el regreso a su isla en 1938. Esta nueva etapa cubana se inaugura con la publicación en español de Cuentos negros de Cuba en 1940 y constituye un período de trabajo de campo sistemático con los descendientes de esclavos en los barrios de La Habana, pero también en Matanzas y Trinidad, que se prolongará hasta su salida de Cuba hacia el exilio norteamericano el 24 de julio de 1960. Instalada en la quinta San José, una vieja finca colonial situada en el barrio de Marianao en La Habana, propiedad de la familia de su compañera, la archivera e historiógrafa María Teresa de Rojas, recibe a sus colaboradores - Teresa Muñoz (Omí Tomî), Calixta Morales (Oddedeî), José de Calazán Herrera (Bangoché), etc.- y comienza a recoger de ellos cuentos, refranes o leyendas de origen africano que seguirá publicando en libros como ¿Por qué? Cuentos negros de Cuba (1948), Refranes de negros viejos (1955), Ayapá: cuentos de Jicotea (1971), etc. ${ }^{8}$.

Paralelamente, aborda la documentación de las cosmogonías y las formas rituales de los principales cultos religiosos desarrollados en Cuba por los esclavos de distintos orígenes africanos. Libreta tras libreta va estableciendo las características y las diferencias de las distintas "reglas" sincretizadas en Cuba por los esclavizados a partir de los dioses y las creencias trasladadas y trasplantadas con ellos tras su desarraigo africano. En 1954 aparecerá el libro fundamental en su trayectoria investigadora y que sigue siendo aún hoy una guía para los practicantes de la Santería y otras religiones afrocubanas, El Monte,

8. La relación de la homosexualidad de Lydia Cabrera, la sororidad establecida con otras mujeres y su trabajo etnográfico con los oficiantes religiosos de los diferentes cultos afrocubanos ha sido puesto de relieve por algunas estudiosas de su obra (Rodriguez-Mangual, 2004; Cuesta, 2015; Sánchez Morales, 2016; Ortiz García, 2020). 
y en trabajos posteriores irá profundizando en cada una de las religiones afrocubanas más importantes (Cabrera, 1959, 1974, 1977, 1979, 1980).

El Monte es el lugar donde residen los dioses, no necesariamente la selva, sino cualquier espacio silvestre en el que encontrar las "yerbas", las plantas poderosas que son posesión de los dioses. Así, el libro está dedicado en una primera parte a la descripción de los orichas, sus orígenes y poderes; mientras que la segunda parte consiste en un catálogo descriptivo, por orden alfabético, de 555 plantas empleadas en los rituales. La forma polifónica en que los distintos informantes de Cabrera aparecen expresándose en $E l$ Monte ha convertido a este libro en un interesante precedente de las monografías de la antropología postmoderna, basadas en la traducción intersubjetiva y la relación dialógica entre el observador u observadora y sus colaboradores (Rodriguez-Mangual, 2004).

La obra de Lydia Cabrera conforma una unidad a lo largo de su vida en Cuba y los años de su exilio en Miami. No obstante, el destierro, debido a su abierta oposición al régimen de Castro, supone un corte enorme en su vida y su trayectoria investigadora, porque la desarraiga de su terreno familiar y la separa del motor de su creatividad y su trabajo intelectual: los afrocubanos. Su último trabajo de campo en Cuba fue el que, en 1956, realiza en el central azucarero “Cuba” en Matanzas, propiedad de la familia de otra buena amiga y colaboradora, Josefina Tarafa. En las cercanías del central se encontraba la laguna de San Joaquín, lugar sagrado de peregrinación para rendir culto a Yemayá (Cabrera, 1973). Junto a las notas tomadas por Cabrera de sus informantes, Josefina Tarafa tomó la documentación fotográfica y ambas grabaron una histórica colección de cantos rituales que posteriormente serían editados en una colección de catorce discos titulada La música de los cultos africanos en Cuba.

El libro resultado de este viaje no se publicó hasta 1973 y, de hecho, durante casi diez años después de establecerse en Miami no escribió más libros. Sin embargo, con ella habían viajado desde Cuba sus cuadernos de notas y, aunque no se sentía atraída por los nuevos establecimientos y oficiantes religiosos dedicados a la santería en Miami, siguió publicando libros y artículos con el material acumulado en sus trabajos de campo en La Habana y Matanzas hasta una edad muy avanzada.

Como se ha visto en el caso de las mujeres investigadoras anteriores, tampoco Lydia Cabrera estuvo sola en el interés y la reivindicación de la cultura y las expresiones artísticas de los afrocubanos. Así, además de Lachatañeré y Ortiz, y antes de la que será la figura dominante en el estudio de la música afrocubana en el periodo de la Revolución, María Teresa Linares, hubo otra mujer famosa y popular en su tiempo, dedicada a interpretar los rezos y cantos religiosos tradicionales en teatros y en discos: Merceditas Valdés (19221996), la pequeña “Aché” de Cuba. 
La condición académica periférica y autodidacta de Lydia Cabrera, su dedicación a la literatura a la vez que a la etnografía, su relegación profesional como mujer, el ostracismo de su exilio, el silenciamiento de su figura y sus trabajos por parte del régimen revolucionario en el interior de Cuba y, finalmente, su dedicación exclusiva a los afrocubanos, son elementos que explican que, a lo largo de muchos años, su enorme y esplendida obra haya quedado al margen de las historias oficiales de la antropología americana en general y cubana en particular (Ortiz García, 2020). No obstante, subterráneamente sus cuentos y los relatos de sus colaboradores han seguido circulando de mano en mano y servido como auténticos manuales de la práctica ritual en la santería $\mathrm{y}$ otras religiones afrocubanas.

Como puede también decirse de las anteriores investigadoras que hemos citado, se produce en Cuba, en niveles oficiales, una cierta continuidad y recuperación de los trabajos y la figura de Lydia Cabrera, tímidamente primero y de una forma más clara a partir de la década de los 90. A pesar de haber estado prohibidos sus libros por el castrismo, se han reeditado recientemente por la editorial Letras Cubanas y la memoria de su trabajo ha sido igualmente destacada por algunas estudiosas actuales, como Natalia Bolívar. Esta gran especialista en las religiones afrocubanas ha reivindicado la influencia recibida y su trabajo de juventud en el montaje de la Sala Afrocubana del Museo Nacional, que fue encargada a Cabrera en 1955 y en la que Bolívar colaboró hasta que fue detenida por la policía de Batista en 1958 (Bolívar, 2000: 33-34).

\section{CONCLUSIONES}

Las complejas relaciones mantenidas por las políticas culturales de los distintos periodos de la Revolución cubana con respecto a los intelectuales republicanos anteriores y, especialmente, con quienes marcharon al exilio, aparecen en toda su complicación y sus contradicciones en estas vidas y trayectorias investigadoras que han ido siendo recuperadas, lenta, pero paulatinamente, tendiendo algunos hilos de continuidad entre los precedentes que pusieron las primeras bases para la construcción de la identidad nacional y el momento presente, en que estas identidades no pueden dejar de verse como multifacéticas y contradictorias (Alonso, 2018).

En estas tres mujeres en torno a las cuales hemos centrado, de modo principal, esta exposición, vemos aparecer una serie de rasgos comunes. En primer lugar, su pertenencia a las élites políticas de la nueva República de Cuba, incluyendo su implicación ideológica, tanto con los distintos gobiernos y regímenes políticos, como en la configuración de las instituciones educativas e investigadoras. Se trata, por tanto, de personas comprometidas con la configuración de un conocimiento en torno a los fundamentos étnicos de la nación, tras el periodo colonial, durante el cual el sistema esclavista se había constituido en el fundamento del poder político y económico. 
En ellas se aprecia también la cercanía que tuvieron con la figura de Fernando Ortiz, considerado el "fundador" de la antropología cubana. Sin que ninguna de ellas tuviera una relación de dependencia con respecto a él, ni tampoco puedan considerarse discípulas en un sentido estricto, sí que participaron en muchos de los ámbitos institucionales creados por Ortiz para servir precisamente al conocimiento que a todas interesaba: la configuración cultural y la identidad étnica de su propia nación. No obstante, la identificación que en este texto se hace de ellas con las ideas de Ortiz expresadas en la metáfora del ajiaco cubano no debe interpretarse como un plan o estrategia organizada por el propio Ortiz, pero tampoco como si se tratase de una idea asumida y encarnada por las mujeres investigadoras que nos han ocupado. Simplemente, se quiere exponer cómo en torno a una figura central que se impone en el relato histórico como única o excepcional, siempre aparecen otras muchas personalidades contribuyendo a la creación y difusión del conocimiento y a la configuración de un ámbito público e institucional propicio para la investigación social. Así, la independencia delas trayectorias profesionales y personales de Guiteras, Poncet y Cabrera con respecto a la figura patriarcal de Ortiz debe ser valorada, con independencia de su cercanía cronológica e incluso vital.

Por otra parte, aunque hayamos focalizado el análisis en tres figuras, en realidad vemos cómo son muchas más las mujeres que, en relación con ellas o de forma independiente, llevaron a cabo investigaciones y mantuvieron iniciativas profesionales destacables. Así pues, aunque pensemos que Guiteras, Poncet y Cabrera fueron tres hitos fundamentales de los estudios sobre la cultura popular y tradicional cubana, ello no supone asumir una historia personalista de la investigación folklórica en Cuba. Bien al contrario, en este trabajo se insiste no solo en la cantidad de profesionales que emergen nada más prestar atención a las iniciativas y a las publicaciones de cada momento, sino también en la capacidad de continuidad y permanencia de las mismas a lo largo de varias etapas históricas.

En otro orden de cosas, en todas las figuras estudiadas en este artículo existe un elemento en común que atañe a los enfoques de género en la historia de las ciencias. Dentro de ellas, las humanidades son un ámbito donde la presencia y la importancia de las mujeres ha sido tradicionalmente mayor que en otras disciplinas categorizadas como ciencias "duras", como la física o las matemáticas. El folklore se ha considerado generalmente como algo útil para enculturar a las personas en los valores de determinadas características del "pueblo", no exactamente concebido como el conjunto de ciudadanos, sino como una especie de raíz ancestral y primigenia que proporciona identidad cultural, pero también política, a la nación. Al ser entendido como el conjunto de expresiones de tipo artístico y popular de un determinado "pueblo", sin entrar en distinciones más problemáticas de clase o de otro tipo, ha sido visto por muchos como una disciplina "blanda", o fácil o amable y, por tanto, y según la división tradicional de roles masculinos y femeninos, una 
actividad propia para ser practicada por las mujeres. Por otro lado, la enseñanza, sobre todo en los niveles inferiores, primarios y secundarios, ha constituido también un nicho profesional históricamente muy feminizado. La unión, en varios de los currículos de las investigadoras que hemos estudiado, de pedagogía y estudios folklóricos, indica una buena sintonía entre estos dos campos desempeñados por mujeres.

Finalmente, las líneas de ruptura y continuidad en las obras de las investigadoras que hemos expuesto reflejan las dificultades de muchas de ellas para formar parte de la narrativa "oficial" o académicamente paradigmática de su disciplina. Aunque, finalmente, casi todas han obtenido en los tiempos actuales un cierto reconocimiento de su labor, también podemos apreciar cómo han sido relegadas por diversas causas. En el caso de Calixta Guiteras, el motivo fue que no realizó etnografía dedicada a temas cubanos. La obra de Carolina Poncet reivindicaba la tradición colonial hispánica y católica, lo que no era precisamente algo muy valorado en la república independiente. Sus discípulas maestras se dedicaban a las formas expresivas infantiles, un tema poco importante desde la perspectiva académicamente dominante. Lydia Cabrera - ella sí dedicada a un sujeto cuya importancia no se podía obviar: los africanos esclavizados-, sin embargo, no pertenecía a ningún medio profesional, era conservadora ideológicamente, exiliada y lesbiana, en un mundo marcadamente patriarcal. En este último caso es tal vez donde aparece más claramente cómo su misma condición de género estuvo también presente para quedar relegada en la nómina de intelectuales que configuran la contribución desde Cuba a la cultura y el conocimiento científico. Pero, en general, el género yla consideración secundaria de las mujeres en la práctica científica es un elemento de discriminación que subyace en las trayectorias de todas las investigadoras que han aparecido a lo largo de este texto. 


\section{REFERENCIAS BIBLIOGRÁFICAS}

Aguirre, Mirta (1985) “El romancero." En La lírica castellana hasta los Siglos de Oro. La Habana: Editorial Letras Cubanas, I, pp. 469-534.

(1975) "El romance en Cuba y en otros países de América Latina”. Islas, 51: 217235.

Alonso, Pablo (2018) Cuban Cultural Heritage. A Rebel Past for a Revolutionary Nation. Gainsville: University Press of Florida.

Alzola, Concepción Teresa (2009) Trayectoria de la mujer cubana. Miami: Ediciones Universal.

(1987b) "Lexicografía de los cuentos negros de Cuba". En Isabel Castellanos y Josefina Inclán (eds.) En torno a Lydia Cabrera (cincuentenario de "Cuentos negros de Cuba", 1936-1986). Miami: Ediciones Universal, pp. 204-210.

(1987a) Habla tradicional de Cuba: Refranero familiar. Miami: Asociación de Hispanistas de las Américas.

(1975) La mas fermosa: [leyendas cubanas]. Miami: Ediciones Universal.

(1961-1962) Folklore del niño cubano. Santa Clara: Dirección de Investigaciones

Folklóricas. Universidad Central de Las Villas, 2 vols. Tomo 1. Formas cantadas. Tomo 2. Juegos.

Arissó, Ana María (1940) Folk-lore saguero. La Habana: Editorial Guerrero.

Barnet, Miguel (1983) La fuente viva. La Habana: Editorial Letras Cubanas.

Barreal, Isaac (2001) Retorno a las raíces. La Habana: Fundación Fernando Ortiz.

Benítez Rojo, Antonio (1989) La isla que se repite. El Caribe y la perspectiva postmoderna. Hanover: Ediciones del Norte.

Bolívar, Natalia (2000) “Tributo necesario a Lydia Cabrera y sus egguns". Catauro. Revista Cubana de Antropología, 1(1): 29-35.

Bolufer, Mónica (2014) "Multitudes del yo: biografía e historia de las mujeres". Ayer, 93(1): 85-116.

Bronfman, Alejandra (2004) Measures of Equality. Social Science, Citizenship and Race in Cuba, 1902-1940. Chapel Hill-Londres: University of North Carolina Press.

Cabrera, Lydia (1980) Koeko iyawó, aprende novicia: pequeño tratado de Regla Lucumí. Miami: Ultra Graphics Corp. (1974) Yemayá y Ochún. Kariocha, Iyalorichas y Olorichas. Madrid: Ediciones C.

$\mathrm{R}$. 
(1973) La laguna sagrada de San Joaquín. Madrid: Ediciones Erre.

(1971) Ayapá: cuentos de Jicotea. Miami: Ediciones Universal.

(1958) La sociedad secreta Abakuá, narrada por viejos adeptos. La Habana: Ediciones C. R.

(1955) Refranes de negros viejos. La Habana: Ediciones C. R.

(1954) El Monte: igbo finda, ewe orisha, vititinfinda (Notas sobre las religiones, la magia, las supersticiones y el folklore de los negros criollos y del pueblo de Cuba). La Habana: Ediciones C.R.

(1948) ¿Por qué? Cuentos negros de Cuba. La Habana: Ediciones C. R.

(1936) Contes nègres de Cuba. París: Gallimard, 1936. Edición en español: Cuentos negros de Cuba. La Habana: Imprenta La Verónica, 1940. Prólogo de Fernando Ortiz.

Castellanos, Isabel y Josefina Inclán (eds.) (1987) En torno a Lydia Cabrera. Miami: Ediciones Universal.

Castellanos, José (2003) Pioneros de la etnografía afrocubana: Fernando Ortiz, Rómulo Lachatañeré, Lydia Cabrera. Miami: Ediciones Universal.

Castro Guevara, Carlo Antonio (2000) Recuerdo de Calixta Guiteras Holmes (1905-1988). Xalapa: Ediciones Cultura de Veracruz.

Chacón y Calvo, José María (1994 [1960]) “Los días cubanos de Menéndez Pidal.” En Salvador Bueno (ed.) Cubanía y españolidad de José María Chacón y Calvo. La Habana: Letras Cubanas.

(1914) "Romances tradicionales en Cuba: Contribución al estudio del folk-lore cubano". Revista de La Facultad de Letras y Ciencias, 18: 45-121.

Córdova de Fernández, Sofía (1923-1929) "El folklore del niño cubano". Revista de la Facultad de Letras y Ciencias, 33 (3-4) (1923): 268-306; 34 (1-2) (1924): 26-52; 35 (1-2) (1925): 109-156; 35 (3-4) (1925): 361-418. También en Archivos del Folklore Cubano. I (3) (1925): 248-270; I (4) (1925): 356-373; II (1) (1926): 72-82; II (2) (1926): 159-168; II (3) (1926): 247-264; II (4) (1927): 369-386; III (1) (1928): 57-78; III (3) (1928): 257-274; IV (1) (1929): 72-89.

Cuesta, Mabel (2015) "Lydia Cabrera entre amigas. Un tren de sores para una ciénaga cementada”. Cuadernos Hispanoamericanos, 779: 12-23.

Davis, Natalie Zemon (1975) "Women's History in Transition: The European Case". Feminist Studies, 3 (3): 83-103.

De la Fuente, Alejandro (2001) A Nation for All. Race, Inequality and Politics in TwentiethCentury Cuba. Chapel Hill-Londres: The University of Carolina Press. 
Del Río Iglesias, Isabel (2016) María Muñoz de Quevedo. La Escuela Coral Cubana. La Habana: UNEAC- Colección Sur Editores.

Del Toro, Carlos (1996) Fernando Ortiz y la Hispanocubana de Cultura. La Habana: Fundación Fernando Ortiz.

Dianteill, Erwan (1995) Le Savant et le Santero. Naissance de la Science des Religions Afrocubaines (1906-1954). París: L’Harmattan.

Esponda Jimeno, Víctor Manuel y otros (1994) Presencia de Calixta Guiteras en Chiapas. Txtla Gutiérrez, Chiapas: Gobierno del Estado, Instituto Chiapaneco de Cultura, Cuadernos Ocasionales.

Fonseca García, Manuela (1930) "Las supersticiones del escolar cubano". Archivos del Folklore Cubano, V (3): 199-221.

Galván Tudela, José Alberto (2018) "Hacia una historia de la antropología sociocultural en Cuba”. Batey. Revista Cubana de Antropología Sociocultural, 11(12): 4-33.

García-Carranza, Araceli (1970) Bio-bibliografía de don Fernando Ortiz. La Habana: Instituto del Libro.

Gregorio Gil, Carmen (2006) "Contribuciones feministas a problemas epistemológicos de la disciplina antropológica: representación y relaciones de poder”. AIBR. Revista de Anrtropología Iberoamericana, 1(1): 22-39.

Guanche, Jesús y Gertrudis Campos (1986). La ciencia etnológica en Cuba durante el siglo XX. La Habana: Ministerio de Cultura.

Guillama, Ruxandra (2019) "Dos direcciones de un mismo camino: El hispanoamericanismo cultural de José María Chacón y Calvo”. Naveg@merica. Revista electrónica editada por la Asociación Española de Americanistas, 23.

Guiteras Holmes, Calixta (2011) México indígena. Ensayos antropológicos. La Habana: Fundación Fernando Ortiz.

(1965b) Los peligros del alma. Visión del mundo de un tzotzil. México: FCE.

(1965a) “Fernando Ortiz: Palparlo todo, olerlo todo, saborearlo todo". Gaceta de Cuba, 4(42): 4-8.

Gutiérrez, Mariela (1991) El cosmos de Lydia Cabrera: Dioses, animales y hombres. Miami: Ediciones Universal.

Harding, Sandra G. (1995) Ciencia y feminismo. Madrid: Morata. (1998) Is science multicultural? Postcolonialisms, Feminisms, and Epistemologies. Bloomington: Indiana University Press. 
Hernández Suárez, Dolores (1929-1930) “Cuentos recogidos en Camagüey”. Archivos del Folklore Cubano, IV (3) (1929): 251-269; V (1) (1930): 61-70.

Hiriart, Rosario (1983) Lydia Cabrera: vida hecha arte. Miami: Ediciones Universal, 2 a ed.

Jordanova, Ludmilla (1993) "Gender and Historiography of Science", British Journal of the History of Science, 26: 469-483.

Korsbaek, Leif y Barrios Luna, Marcela (2009) "La antropología en Cuba". Cuicuilco, 16(46).

Le Riverend, Julio (1991) “Ortiz y sus contrapunteos". En Fernando Ortiz, Contrapunteo cubano del tabaco y el azúcar. La Habana: Editorial de Ciencias Sociales, pp. 5-29.

Mariscal, Beatriz (1996) Romancero General de Cuba. México: El Colegio de México.

Lescay, Ada (2017) "Lo conceptual, lo descriptivo y lo sistémico en el estudio de las religiones cubanas de origen africano: R. Lachatañeré, L. Cabrera y R. López Valdés". Del Caribe, 67: 36-43.

Linares, María Teresa (1970) La música popular. La Habana: Instituto Cubano del Libro. Linares, María Teresa y Faustino Núñez (1998) La música entre Cuba y España. Madrid: Fundación Autor.

Mayberry, Maralee; Banu Subramaniam, y Lisa Weasel (eds.) (2001) Feminist Science Studies: A New Generation. London-New York: Routledge.

Menéndez Pidal, Ramón (1906) Los romances tradicionales en América. Madrid: Cultura Española.

Mesa, María Eugenia (2008) "José María Chacón y Calvo y Fernando Ortiz: Sociedad del Folklore Cubano y la revista Archivos del Folklore Cubano". Catauro, 9 (17): 74-98.

Miranda, Consuelo (1929) Las supersticiones de los niños cubanos. Archivos del Folklore Cubano, IV (1).

Ortega, J. (2004) "Carolina Poncet y de Cárdenas. Una mujer en las lides del pensamiento". La Jiribilla. Disponible en: http://lajiribilla.co.cu/2004/n170 08/memoria.html [consultado el 10-9-2020].

Ortiz, Fernando (1940) "Los factores humanos de la cubanidad". Revista Bimestre Cubana, XLV: 161-186.

(1924) "Esta revista cubana". Archivos del Folklore Cubano, I(1): 4-8.

Ortiz García, Carmen (2003) "Cultura popular y construcción nacional: la institucionalización de los estudios de folklore en Cuba”. Revista de Indias, LXIII (229): 695-736. 
(2020) "Contrapunteos de Lydia Cabrera”. Arbor. Ciencia, Pensamiento y Cultura, 196(796): a559.

Palmié, Stephan (2013) The Cooking of History. How not to Study Afrocuban Religion. Chicago: University of Chicago Press.

Pérez Álvarez, Frank (2011) Carta a Rafael Rojas. Blog. Libros del Crepúsculo, 28-102011. Disponible en: http://www.librosdelcrepusculo.net/ [consultado el 10-9-2020].

Pérez Valdés, Trinidad (comp.) (2014-2016) Correspondencia de Fernando Ortiz. Valencia: Fundación Fernando Ortiz, 3 vols.

Poncet y de Cárdenas, Carolina (2004) Reflexiones teórico-prácticas desde las ciencias de la educación. La Habana: Editorial Pueblo y Educación.

(1985) Investigaciones y apuntes literarios. Ed. y prólogo de Mirta Aguirre. La Habana: Letras Cubanas.

(1972) El romance en Cuba, La Habana: Instituto Cubano del Libro.

(1947) Lecciones de lenguaje. La Habana: Ediciones UCAN, S.A.

(1930) “Romances de Pasión”. Archivos del Folklore Cubano, V (1): 5-29.

(1926) "Los altares de cruz". Archivos del Folklore Cubano, II (2): 97-102.

(1924) “Cantares locales cubanos”. Archivos del Folklore Cubano, I (2): 97-102.

(1923) "Romancerillo de Entrepeñas y Villar de los Pisones". Revue Hispanique, 58: 286-314. Tambien en Archivos del Folklore Cubano, III(2) (1928): 121-154.

(1914) "El Romance en Cuba". Revista de la Facultad de Letras y Ciencias de la Universidad de La Habana, XVIII (2 y 3). Reed. El romance en Cuba. La Habana: Fundación Fernando Ortiz, 1999.

Prat, José (2008) Bajo el árbol del Paraíso: historia de los estudios sobre el folclore y sus paradigmas. Madrid: CSIC.

Puig-Samper, Miguel Ángel y Consuelo Naranjo (2001) "La acogida del exilio español en Cuba: Fernando Ortiz y la Institución Hispanocubana de Cultura". Ibero-Americana Pragensia. Suplementum, 9: 199-213.

Quiza, Ricardo (2014) New Knowledge for New Times. The Sociedad del Folklore Cubano during the 'Critical Decade' (1923-1930), Steven Palmer; José A. Piqueras y Amparo Sánchez Cobos (eds.) State of Ambiguity: Civic Life and Culture in Cuba's First Republic. Durham: Duke University Press.

Rangel Rivero, Armando (2012) Antropología en Cuba. Orígenes y desarrollo. La Habana: Fundación Fernando Ortiz. 
Rodriguez-Mangual, Edna M. (2004) Lydia Cabrera and the Construction of an AfroCuban Cultural Identity. Chapel Hill: University of North Carolina Press.

Sánchez Morales, María G. (2016) Diosas de ébano para Cuentos negros de Cuba de Lydia Cabrera. Tesis doctoral. Las Palmas de Gran Canaria: Universidad de Las Palmas de Gran Canaria.

Santesmases, María Jesús; Montserrat Cabré y Teresa Ortiz (2017) "Feminismos biográficos: aportaciones desde la historia de la ciencia”. Arenal, 24(2): 379-404.

Santí, Enrico M. (2002) Fernando Ortiz: contrapunteo y transculturación. Madrid: Ed. Colibrí.

Stolke, Verena (1993) "De padres, filiaciones y malas memorias ¿qué historias de qué antropologías?", Joan Bestard (ed.), Después de Malinowski. Santa Cruz de Tenerife: Federación de Asociaciones de Antropología del Estado Español. Asociación Canaria de Antropología, pp. 147-198.

Trapero, Máximiano y Marta Esquenazi (2002) Romancero tradicional y general de Cuba. Madrid: Gobierno de Canarias-Centro de Investigación y Desarrollo de la Cultura Cubana "Juan Marinello". 